\title{
Pulmonary large-cell neuroendocrine carcinoma presenting as multiple cutaneous metastases
}

\author{
Carcinoma neuroendócrino de grandes células do pulmão \\ diagnosticado a partir de múltiplas metástases cutâneas
}

\author{
Tiago Mestre', Ana Maria Rodrigues ${ }^{2}$, Jorge Cardoso ${ }^{3}$
}

\section{To the Editor:}

Here, we describe the case of a 66-year-old, male nonsmoker with a history of type 2 diabetes mellitus, hypertension, and dyslipidemia. The patient was referred to our hospital after the emergence of four painful erythematous nodules on his face, scalp, and trunk, over a three-week period (Figure 1). Determination of tumor markers showed elevated levels of procalcitonin (30.83 ng/ $\mathrm{mL}$; reference value, $<0.5 \mathrm{ng} / \mathrm{mL}$ ), carbohydrate antigen 19-9 (2,700 U/mL; reference value, < $37 \mathrm{U} /$ $\mathrm{mL}$ ), and lactate dehydrogenase (850 $\mathrm{U} / \mathrm{L}$; reference range, 313-618 U/L). The histopathological examination of two nodules revealed strands and nests of large pleomorphic cells with vesicular nuclei and prominent nucleoli. Tumor cells were found to be immunohistochemically positive for chromogranin A, synaptophysin, and CD56 (Figure 2), as well as for cytokeratin 7 , whereas they were immunohistochemically negative for CD20. A CT scan of the chest revealed a $4-\mathrm{cm}$ mass in the left lower lobe (Figure 1). The results of a transbronchial biopsy (via bronchoscopy) confirmed the diagnostic hypothesis of largecell neuroendocrine carcinoma (LCNEC) of the lung. The patient died three months after the diagnosis.

Cutaneous metastases are a sign of poor prognosis. They are the first sign of an internal malignancy in only $0.8 \%$ of cases. The neoplasms that most often present as cutaneous metastasis are breast cancer in women and lung carcinoma in men. Cutaneous metastases can have a multitude of presentations, the abdomen, chest, scalp, and face being the sites that are most often affected. ${ }^{(1)}$

Only $0.3 \%$ of all lung cancers are LCNECs, which rarely present as cutaneous metastasis. The typical LCNEC patient is a male smoker in the seventh decade of life. ${ }^{(2)}$ This type of carcinoma has an aggressive course and is rapidly metastatic. However, LCNEC rarely presents as endocrine syndromes, cutaneous metastases, or involvement of the surrounding structures. It can occur in the lungs, breasts, uterine cervix, gallbladder, urinary bladder, and ovaries, as well as (rarely) in the colon. ${ }^{(3,4)}$ There have been only four reported cases of LCNEC presenting as cutaneous metastasis, and the primary origin of the neoplasia (lung, bladder, and rectum, respectively) was identified in three of those cases. ${ }^{(3-5)}$ The case in which the origin could not be identified was the only one in which multiple cutaneous metastases occurred. To our knowledge, ours is the first report of multiple cutaneous metastases as the presenting sign of LCNEC of the lung. When there is no extracutaneous involvement, excision of cutaneous metastases of LCNEC should be considered because it could increase survival. If there are internal metastases, chemotherapy should be considered the first-line treatment, albeit having been shown to elicit a weak response. Survival after cutaneous metastasis ranges from two to five months. ${ }^{(6)}$ It is important to distinguish cutaneous metastases of LCNEC from Merkel cell carcinoma, a rare lesion seen mainly in areas of the skin that have been exposed to the sun. ${ }^{(3)}$ In the latter, the cells are usually smaller and are cytokeratin 20-positive. ${ }^{(3)}$

The case presented here helps clarify the biological behavior and the immunohistochemical profile of LCNEC of the lung. Our findings also underscore the importance of early recognition of cutaneous metastases to the accurate diagnosis and prompt, appropriate treatment of neoplasia.

1. Resident in Dermatology, Department of Dermatology, Curry Cabral Hospital, Centro Hospitalar de Lisboa Central, Lisbon, Portugal 2. Senior Consultant, Department of Dermatology, Curry Cabral Hospital, Centro Hospitalar de Lisboa Central, Lisbon, Portugal 3. Head, Department of Dermatology, Curry Cabral Hospital, Centro Hospitalar de Lisboa Central, Central Lisbon Hospital Center - Lisbon, Portugal 


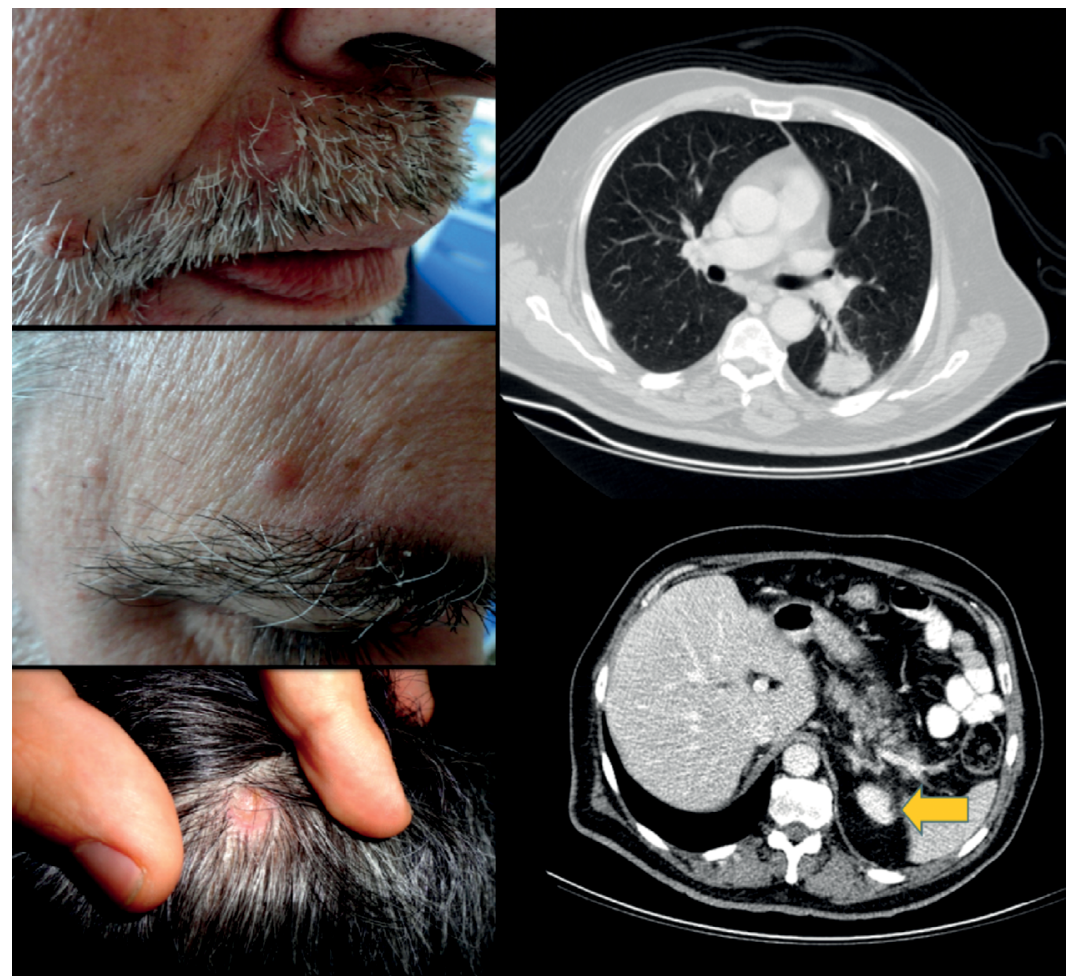

Figure 1 - Eruptive painful erythematous nodules on the face and scalp (photographs on the left). CT scans (on the right) revealed a 4-cm mass in the left lower lobe. Note the left adrenal gland metastasis (arrow).

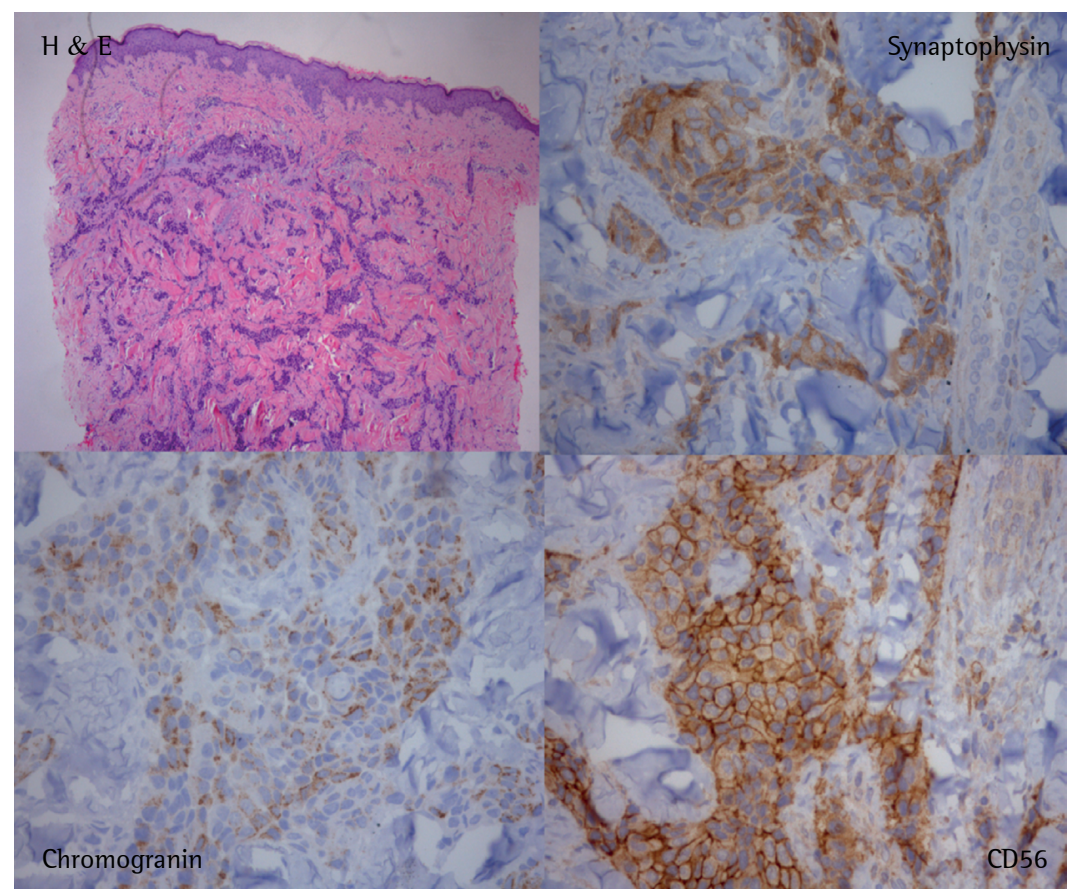

Figure 2 - On the upper left, histopathological staining showing sheets of pleomorphic tumor cells with a trabecular growth pattern in the dermis (HEtE; magnification, $\times 100$ ). Immunohistochemical staining for CD56 showed positivity for tumor cells in a cytoplasmic pattern (lower right). Tumor cells were focally positive for chromogranin (lower left) and synaptophysin (upper right). 


\section{References}

1. Ardavanis A, Orphanos G, loannidis G, Rigatos G. Skin metastases from primary lung cancer. Report of three cases and a brief review. In Vivo. 2006;20(5):671-3.

2. Gustafsson Bl, Kidd M, Chan A, Malfertheiner MV, Modlin IM. Bronchopulmonary neuroendocrine tumors. Cancer. 2008;113(1):5-21. http://dx.doi.org/10.1002/ cncr.23542

3. Shin MK, Choi CM, Oh YJ, Kim Nl. CK20 Positive Largecell Neuroendocrine Carcinoma Presenting with Skin Metastases. Ann Dermatol. 2011;23 Suppl 1:S20-4. http://dx.doi.org/10.5021/ad.2011.23.S1.S20
4. Yuan C, Keating B, Farricielli LA, Z Kuixing. Large-cell neuroendocrine carcinoma (LCNEC) without pulmonary symptoms diagnosed in a cutaneous metastasis. Am J Case Rep. 2014;15:97-102. http://dx.doi.org/10.12659/ AJCR.890094

5. Lee WJ, Kim CH, Chang SE, Lee MW, Choi JH, Moon KC, et al. Cutaneous metastasis from large-cell neuroendocrine carcinoma of the urinary bladder expressing CK20 and TTF-1. Am J Dermatopathol. 2009;31(2):166-9. http:// dx.doi.org/10.1097/DAD.0b013e31818eba4c

6. Beachkofsky TM, Wisco OJ, Osswald SS, Osswald MB, Hodson DS. Pulmonary cutaneous metastasis: a case report and review of common cutaneous metastases. Cutis. 2009;84(6):315-22. 